\title{
UN BALANCE EDITORIAL DE BIOLOGICAL RESEARCH
}

$\mathrm{L}$ a investigación que se realiza en Chile, de escasa a creciente, siempre exhibió los atributos que se exigen a la generación de conocimientos en el contexto de su validación internacional. Es más, siempre fue así considerada por la comunidad científica. No puede decirse lo mismo respecto a la percepción de muchos en lo que concierne a las revistas. Pareciera que por el hecho de ser editadas en el país se les atribuyere un carácter más bien aldeano, y, en consecuencia, de escasa necesidad, repercusión y visibilidad internacional. Todavía hay concursos públicos que por desconocimiento o ignorancia discriminan las publicaciones "nacionales" en revistas chilenas de solvencia internacional acreditada, lo que revela una de las variadas debilidades de nuestras políticas públicas para la ciencia.

Inmerso en un escenario que mantiene alguna de las características descritas, es oportuno hacer un sucinto recuento de la relevancia internacional de Biological Research. También de los aciertos editoriales. Hoy se puede acreditar que la revista, reconocida por importantes y exigentes registros, accesible en línea a través de www.scielo.cl, es muy leída. El artículo de Urquiaga y Leighton ${ }^{1}$ publicado el año 2000 en un número especial editado por el Dr. F. Leighton ha sido requerido en línea más de 4.630 veces. Artículos más recientes, como el de Medina y Owen ${ }^{2}$, ya consignan sobre 1.250 bajadas en escasos dos años. Entre los números que se destacan, es justo distinguir el sobresaliente esfuerzo de los Dres. Lisette Leyton y Andrew Quest, quienes abordando el tema de "Supramolecular Complex Formation in Signaling and Disease", editaron los trabajos presentados en un encuentro científico organizado por ellos, y tan solo en dos años los 21 artículos publicados provocaron 151 citaciones en revistas de corriente principal. Liderando el número en comento, destaca el artículo de Arthur et al. $(2002)^{3}$ con 20 citas al mes de agosto del año 2004, 12 de las cuales corresponden a este año e incidirán positivamente en el factor de impacto de la revista, el más alto en su categoría en Latinoamérica. Le sigue en impacto el artículo de Thomas $(2002)^{4}$ con 15 citas en este lapso de tiempo, más de la mitad, también de este año. Es claro que, medido por las citas generadas, el número de Biological Research editado por Lyon y Quest debe ser reconocido como el que aportará el mayor impacto de la revista desde que su edición verifica sistemáticamente con indicadores internacionales el impacto temprano que provoca.

Chile lidera la edición de revistas de corriente principal en la región con relación a la población del país. Las políticas públicas para la ciencia y la tecnología exigen cada vez más profesionalismo. Lo mismo las revistas. Biological Research es un buen ejemplo que amalgama los propósitos de la Sociedad de Biología de Chile con la necesaria notarialización de los resultados de la mejor ciencia que se hace en el mundo. Sin embargo, si bien los indicadores son imprescindibles para el seguimiento y autoevaluación de una revista de corriente principal, la capacidad científica de un país ni de institución alguna se puede acrecentar sin comprender la raíz de cada cifra, sus limitaciones y su necesaria ponderación.

\section{MANUEL KRAUSKOPF*}

1 URQUiagA I, LEIGHTON, F (2000) Plant Polyphenol Antioxidants and Oxidative Stress. Biol Res 33: 55-64.

2 MEDINA, R, OWEN G (2002) Glucose transporters: expression, regulation and cancer. Biol Res 35: 9-26

3 ARTHUR WT, NOREN NK, BURRIDGE K (2002) Regulation of Rho family GTPases by cell-cell and cell-matrix adhesion. Biol Res 35: 239-246

4 THOMAS G (2002) The S6 kinase signaling pathway in the control of development and growth. Biol Res 35: 305-313

* Editor de Biological Research

Universidad Andrés Bello, Instituto Milenio de Biología Fundamental y Aplicada.

Santiago, Chile mkrausk@unab.cl 